\title{
Knowing our Users: Deriving Value from the Ithaka $S+R$ Local Surveys at the University of Missouri
}

\author{
Jeannette E. Pierce, Shannon Cary, Gwen Gray, and Caryn Scoville \\ University of Missouri, USA
}

\section{Introduction}

Founded in 1839 as the first public university west of the Mississippi River, the University of Missouri (MU) has an enrollment of over 30,000 students from around the state, nation, and globe. MU is a comprehensive educational institution with more than 300 degree programs and is one of only six public universities in the US that claim a medical, veterinary, and law school on the same campus. MU is also one of only 60 public and private US universities invited to membership in the Association of American Universities (AAU). This year we are celebrating our first Nobel Prize winner, George P. Smith. The University of Missouri Libraries belong to the Association of Research Libraries (ARL), the Greater Western Library Alliance (GWLA), and the statewide MOBIUS consortium.

In 2017, the libraries worked with Ithaka S+R to distribute the Ithaka S+R Local Graduate Student Survey and the Ithaka S+R Local Faculty Survey with the goal of gathering information from these user groups to help us evaluate our services and inform strategic planning for the future. A secondary goal was to use evidence derived from the results to engage campus partners in the process of helping us define and evolve our services, especially those related to emerging aspects of scholarly communication, research data management, and space planning.

\section{Background}

For more than a decade the libraries have been making important changes to our operations as a result of scholarly content moving online and our need to preserve knowledge, both print and digital, for future generations. Many of our traditional services, such as print collections, are still in high demand, yet we find we must dedicate an increased number of staff to new areas such as managing and preserving digital content. In support of researchers, our librarians are on the front lines of a battle to rein in the costs of scholarly communication by advocating for open access and digital curation initiatives that make content accessible to all. The libraries have an established institutional repository and work with faculty on open access, data management, author identify management, and scholarly metrics. As teaching pedagogy has moved to incorporate more active learning, team projects, and knowledge creation, our library spaces have been transforming to meet the learning and technology needs of today's students.

The libraries have an assessment team made up of the associate director for research, access, and instructional services, our communications officer, and two faculty librarians. We do not have dedicated assessment staff. Implementation and analysis of large-scale surveys is not something we attempt to do annually due to the costs involved, both in terms of fees and staff time. Prior to 2017, the libraries had conducted ARL's LibQUAL survey in 2003 and LibQUAL Lite in 2012. Though we saw value in repeating LibQUAL Lite again, the committee investigated the Ithaka surveys as an option that could aid us in campus conversations about our strategic directions by providing more data about how our users accomplish their scholarly work.

The libraries' management team approved implementation of the Ithaka S+R Local Faculty Survey and Local Graduate Student Survey in August 2017. To keep costs and our commitment of staff time manageable, we chose not to implement the undergraduate student survey in 2017. We also determined not to contract with Ithaka $\mathrm{S}+\mathrm{R}$ for a custom analysis of the survey data. Though our assessment team proposed a spring 2018 implementation, we were encouraged to implement in October 2017 in order to be able to use data for strategic planning as soon as possible. 


\section{Survey Implementation}

With the decision to launch the survey on October 2, our team began preparations in earnest. We first contacted the Provost's Office and the Office of Institutional Research (IR) to ensure support from the provost and that we would not be conflicting with another major survey effort on campus. IR staff worked closely with us to create the faculty survey population distribution list, provide official lists of academic departments that allowed us to customize demographic questions, and to test the survey instrument. They also advised us on working with the campus Institutional Review Board (IRB), with other campus partners such as IT for white listing, and with Student Information Systems for preparation of the graduate and professional student survey population list. We contacted our law library-an administratively-separate library on campus - to determine whether law faculty and students would participate in the survey.

Ultimately, they decided this was not the right time for them. One other partner that we consulted was the Office of Graduate Studies. The associate vice chancellor for graduate studies reviewed the survey instrument and sent us several requests for minor changes that we were able to implement. We were very grateful to Christine Wolff Eisenberg at Ithaka for her steady guidance, patience, and quick responses to our many questions between mid-August and the October launch. We spent the most time on the following activities: selecting additional survey modules; determining who would receive additional survey modules; customizing some aspects of each survey; finalizing a faculty population list; and deciding upon survey incentives.

It took several phone meetings with Ithaka to come to a decision about which modules to add to the core survey. Looking closely at the module questions, understanding how the modules could be distributed, and debating on the merits of adding any additional length to the survey was a lengthy process. Ultimately, in consultation with our libraries' management team, we determined that faculty would randomly receive either the library space planning or the scholarly communication and market research modules. Graduate and professional students would receive either library space planning or research practices. We chose space planning for both surveys in anticipation of expanding our off-site shelving facility, which would lead to some opportunities to develop our existing on-campus spaces. Scholarly communication and research practices, and to some extent, market research, were chosen to help us with strategic conversations about the role of libraries in supporting access to scholarship, publishing, open access, and data management.

In consultation with IR and the Office of Graduate Studies, our team added or modified questions in both surveys. Changes to both surveys included:

- Changing the language "library building" to "campus library location" with added drop-downs for specific campus libraries to better reflect our special libraries that operate in specific schools/colleges

- Adding the name of our institutional repository to relevant questions

Changes to the faculty survey included:

- Adding a demographic question to identify primary college/school and department

- Adding a demographic question to identify faculty rank

- Removing some questions from the "Market Research" module to reduce the length of the survey

Changes to the graduate student survey included:

- Adding primary college/school and department

- Adding a demographic question to help us determine the degree to which the responder was an online student, as defined by the University of Missouri. We worked on this question with the director of our distance learning program.

- Ensuring that language referring to degree programs was consistent with our campus

- Modifying the question about forms of employment to include assistantships 
- Requesting that one non-demographic question from the core questions be included in our stratified response results in order to allow us to more easily look at results for MA students versus PhD students

Questions from IR regarding which faculty would receive the survey proved to be more time-consuming than anticipated, especially when we looked at faculty who were instructors under University of Missouri Extension. For example, some instructors might teach only a few times per year as part of the fire safety training program. We did not include this type of faculty, but in general leaned towards inclusion. In regards to incentives, we wanted to do something other than a gift card drawing, such as offering recipients an option to support a donation to a selected charity. However, upon investigation, other options could not be worked out easily due to campus financial rules. We decided to give survey participants the option to opt-in to a random drawing for a $\$ 25.00$ Amazon gift card after completing the survey. We approved and ultimately distributed ten gift cards to faculty and twenty gift cards to graduate students.

Ultimately, Ithaka sent the survey links and reminders directly to 2,100 faculty and 6,000 graduate and professional students. In addition, our communications officer coordinated a marketing campaign to promote the survey. Once launched, we kept in close touch with Ithaka about response rates and made several efforts to increase the number of survey completions. Ultimately, we were disappointed in the percentage response rate, a consistent $14 \%$ for both surveys. However, campus IR felt that the response rate would still yield valid results and that survey fatigue was a likely factor. It should be noted that a fairly significant number clicked into the survey or started the survey without completing, indicating that our concern about time of completion was a factor. Criticism of the survey length was an oft repeated survey comment. On the plus side, we had good representation across disciplines. We were interested to note that $1 / 3$ of graduate and professional student respondents described themselves as campus students, $1 / 3$ as hybrid campus/online students, and $1 / 3$ as online students. We also noted that more $\mathrm{PhD}$ level graduate and professional students responded than master's degree students.

\section{Key Findings}

We received the survey results from Ithaka right on schedule. This included a full report of aggregated results for each population group, the full data sets for each population, and the stratified data sets for each population. We began by looking at the aggregated data to determine key findings that could be shared with the libraries and our users. Ultimately, we created a summary document for each survey to be released with the full aggregated results.

Both surveys explored perspectives on the role of the library. Responses showed very strong support for our traditional strengths of paying for shared resources and organizing, preserving, and maintaining resources. Here are some of the results that we chose to emphasize in the summaries:

\section{Discovery}

- The library is still used for discovery, but is not always a starting point. However, $73 \%$ of faculty indicated that they see the library as a gateway for locating information.

- Forty percent of graduate and professional students begin research with Google Scholar or JSTOR.

- More than half of faculty respondents felt that undergraduate students have poor skills related to locating and evaluating scholarly information.

- Fifty-nine percent of faculty indicated that librarians contribute significantly to their student's learning.

- A high percentage of graduate students responded that improving their ability to find sources of information on a range of topics was very important or important. However, less than $50 \%$ agree or strongly agree that library staff help them develop research skills and only $31 \%$ have been directed by an instructor to consult with a librarian. 


\section{Collections}

- Both faculty and graduate students continue to value the libraries for providing access to resources needed for research and learning.

- While access to journal articles is the overwhelming need, all types of materials are used.

- The transition to online journals is complete, but the print book is still of high value. Over $50 \%$ of graduate students indicate use of print collections sometimes or regularly.

- Sixty-four percent of our graduate students indicate that accessibility of needed books and journals is an important or very important consideration when choosing a research topic for a dissertation or thesis.

\section{Scholarly Communication}

- Our faculty and graduate students value the principle of public access to research and are supportive of federal mandates. However, few faculty negotiate author agreements.

- Sixty-seven percent of faculty have at least one of their peer-reviewed journal articles or conference proceedings available for free online. Twenty-three percent of respondents have made content available in our local repository. Forty-nine percent of faculty indicate they have published in an open access disciplinary repository.

- A high percentage of faculty respondents would be happy to see the current subscription-based model replaced by an open access publication system.

- Only $37 \%$ of faculty respondents indicate that they consider whether a journal makes articles freely available when deciding on publication.

- There is a need for dissemination support services, such as helping to determine where to publish, negotiating favorable publication contracts, assessing impact, and managing a list of scholarly outputs. Comments suggest that some faculty had never thought of looking to the libraries for these types of services, but could now see why the libraries could be helpful.

\section{Data Management}

- Faculty are producing all types of data.

- Many faculty are confident in their ability to manage data, but some do express difficulty with managing data/media.

- Fifty-one percent of faculty respondents indicated that having the library assist with data management would be valuable.

\section{Space Planning}

- Over $90 \%$ of our faculty have been in a campus library; $60 \%$ had been in within the last month. However, most faculty had a visit duration of under 30 minutes.

- Graduate students use campus libraries for study, access to materials, computing, and printing. Forty-eight percent indicated a stay of more than an hour when they visit the library.

- Our graduate students value access to digital media tools and advanced software applications. Seventy-eight percent indicated that a digital media commons or maker space would be "extremely useful."

- Our graduate students are online and often working part-time or full-time jobs.

- There is a continuing need for more power outlets.

\section{Sharing Results}

Working with the results has been a slow process for us and we plan to continue this work at least through the current academic year. We have completed a summary of key findings for each survey that includes recommendations for library priorities. Recommendations stemming from the faculty survey are:

1. Actively share information with faculty about the cost of access to scholarly publications and work with faculty to support open access as a means to ensure global access to scholarship. 
2. Advocate for library collections that support scholarly research and teaching across the disciplines.

3. Collaborate with Research Computing and the Office of Research to support faculty needing to manage data for preservation and access.

4. Promote best practices for negotiating with publishers, author identity management, and using impact metrics.

5. Assess impact of library support for teaching and work with campus partners on how to best support student learning.

Recommendations stemming from the graduate and professional student survey are:

1. Collaborate with the Office of Graduate Studies and graduate program directors to improve communication with graduate students and graduate advisors about library services and resources.

2. Advocate for collections that support graduate and professional student research across the disciplines.

3. Continue to advance and promote the libraries' capacity to provide services and resources virtually.

4. Work with the University Libraries Student Advisory Council to ensure library spaces provide digital media and software applications that support coursework and research demands.

The summaries of key findings and full aggregated results have been shared with our campus community via our library communication channels, including NewsHub posts and social media. The summaries, along with the full results provided by Ithaka, are posted on our website and can be easily shared with individuals as we continue to talk about them over time. We presented on the results at a library staff advisory group meeting and the documents are posted on our staff website with other reports. We also presented the results to our campus library committee.

Our focus since completing the initial reports has been to use the results as a means of generating discussion with key stakeholders on campus. For example, we met with the vice chancellor for graduate studies to review the results. This gave us an opportunity to explore some of the results and to discuss library priorities. The meeting also helped us to prioritize our need to create new summary reports based on some of the stratified data available to us. Priorities for the Office of Graduate Studies are results by discipline, results by online versus campus student, and results by students in MA versus $\mathrm{PhD}$ programs. Notably, almost half of our graduate students are in online programs and it will be important to look at how their responses compare to campus students. As a further step, our Office of Graduate Studies is very interested in looking at international student responses. Developing a version of the summary report focused on international students could also be shared with the MU International Center and our ESL programs. The associate vice chancellor for graduate studies is supportive of our recommended goals and plans to share our data in meetings with associate deans on campus. At our meeting with the Faculty Affairs Committee of our Faculty Council, we focused on sharing responses related to publishing and data management. We learned there was agreement about the need to address the cost of scholarly journals and that there was some support for the idea of a campus open access policy and reaching out to faculty about opportunities to negotiate publishing contracts.

Internally, we have asked our Instruction Advisory Committee to look closely at all data related to teaching and learning. The goal here is to use some of these data as we speak with departments about how they integrate information literacy into their programs, in our promotional material about library instruction, and in conversations with our new Teaching for Learning Center on campus. We are asking our digital scholarship librarian to take a closer look at data related to open access, author rights, citation metrics, and data management with the goal of sharing this data with our Cyberinfrastructure Council and our associate 
deans of research. Finally, we have asked our e-learning librarian to begin looking at what we need to learn from the results about online students. Some online students indicated in comments that much of the survey was not relevant to them. With growing online programs, we want to ensure that libraries are seen as relevant by this population.

\section{Concluding Thoughts or What We Would Change}

As with most surveys, the survey responses have led to the need to ask more questions. We still need to determine if and how we can dig deeper into these responses. What would we change? Based on survey comments, we would definitely choose no more than one additional module for each survey. With more time, we may have done even more to customize the survey by modifying or eliminating module questions. We would have benefited from a core set of questions for both the faculty and the graduate student surveys that used the same language and response options. Finally, without a sophisticated data analyst at our disposal, the variance in the Likert scales has proven labor intensive for us to work with as we try to present the data. More recently, space planning has become an urgent topic for our libraries. Data from undergraduates would be very helpful for us as we have space conversations with our campus. Given the difficulty we have found in dedicating time to survey analysis and reporting, we may well have been wise to contract with Ithaka for a custom analysis that could have been easily shared with our campus community in a timelier manner. We may have benefited from being able to present an externally produced analysis of the results as an objective picture of how our faculty and graduate students view the role and value of the libraries. Overall, the Ithaka survey results do help us to better understand the goals our users have for their academic teaching, research, and learning. We know more about their thoughts on scholarly communication and data management and have more information that can be used for space planning. Most importantly, the results are giving us a renewed opportunity to discuss our strategic directions with key stakeholders both within and outside of the libraries.

-Copyright 2019 Jeannette E. Pierce, Shannon Cary, Gwen Gray, and Caryn Scoville 